\title{
Pre-Earthquake lonospheric Anomalies Associated with the 2015 Gorkha Earthquake of Nepal Detected by GPS-TEC Measurements
}

Monika Karki

ASCOL: Amrit Science College

Ashok Silwal

Tribhuvan University - Patan Multiple Campus

Narayan Prasad Chapagain

ASCOL: Amrit Science College

Prakash Poudel

Tribhuvan University - Patan Multiple Campus

Sujan Prasad Gautam

Tribhuvan University, Central Department of physics

Binod Adhikari ( $\sim$ binod.adhi@gmail.com )

St.Xavier's College https://orcid.org/0000-0002-2799-9112

\section{Ranjan Kumar Dahal}

Central Department of Geology, Tribhuvan University

\section{Basu Dev Ghimire}

Department of Physics, St. Xavier's College, Maitighar, Kathmandu, Nepal

Roshan Kumar Mishra

Department of Physics, St. Xavier college, Maitighar, Kathmandu, Nepal

\section{Yenca Migoya Orue}

ICTP: Abdus Salam International Centre for Theoretical Physics

\section{Andres Calabia}

Nanjing University of Information Science and Technology

\section{Research}

Keywords: Earthquake, Ionosphere, Total Electron Content, Seismic Waves, lonospheric Anomaly

Posted Date: August 23rd, 2021

DOI: https://doi.org/10.21203/rs.3.rs-786681/v1 
License: (c) (i) This work is licensed under a Creative Commons Attribution 4.0 International License. Read Full License 


\title{
Pre-Earthquake Ionospheric Anomalies Associated with the 2015 Gorkha Earthquake of Nepal Detected by GPS-TEC Measurements
}

Key points:

* Ionospheric electron contents have emerged as one of the main parameters reflecting the behavior of ionospheric as a whole; they can be applied to detect the pre-earthquake ionospheric anomaly.

* TEC anomalies associated with the earthquake's preparation can have a positive or negative sign.

* Variation in ionospheric VTEC almost inversely depends upon the distance of GPS stations from the epicentre.

* The key to determining the underlying physical mechanism of pre-earthquake processes is to investigate all kinds of anomalies in the earth-atmosphere-magnetosphere system simultaneously, try to connect them, and gain a comprehensive understanding of the pre-earthquake modifications of an integrated system.

M. Karki ${ }^{1}$, A. Silwal ${ }^{2}$, N. P. Chapagain ${ }^{1}$, P. Poudel $^{2}$, S. P. Gautam ${ }^{3}$, B. Adhikari ${ }^{4}{ }^{*}$, Ranjan Kumar Dahal $^{5}$, B. D. Ghimire ${ }^{4}$, R. K. Mishra ${ }^{4}$, Yenca Migoya-Orue ${ }^{6}$, Andres Calabia ${ }^{7}$

${ }^{1}$ Amrit Campus, Tribhuvan University, Kathmandu, Nepal

${ }^{2}$ Patan Multiple Campus, Tribhuvan University, Lalitpur, Nepal

${ }^{3}$ Central Department of Physics, Tribhuvan University, Kirtipur, Nepal

${ }^{4}$ Department of Physics, St. Xavier College, Maitighar, Kathmandu

${ }^{5}$ Central Department of Geology, Tribhuvan University, Kirtipur, Kathmandu, Nepal

${ }^{6}$ T/ICT4D laboratory of the Abdus Salam International Center for Theoretical Physics, 34151

Trieste, Italy

${ }^{7}$ Nanjing University of Information Science and Technology, Nanjing, China.

*Corresponding author: binod.adhi@gmail.com

\begin{abstract}
The present study analyses the variations in the ionospheric total electron content (TEC) prior to and during the 2015 Gorkha Earthquake in Nepal $(\mathrm{Mw}=7.8)$ on 25 April 2015, utilising data from the widely distributed Global Positioning System (GPS) network. This study aimed to determine the association between ionospheric TEC anomalies and the occurrence of earthquakes. The finding shows that anomalous TEC changes occurred several days to a few hours prior to the major impending events. The results reveal that deviations in vertical total electron content (VTEC) at distant locations from the epicentre are less than those observed at the epicentre, implying that variation in ionospheric VTEC is nearly inversely proportional to the distance of GPS stations from the epicentre. In view of the solar-terrestrial environment, the pre-earthquake ionospheric anomalies could be associated with the 2015 Gorkha Earthquake. The VTEC anomaly was identified when it
\end{abstract}


crosses the upper bound (UB) or lower bound (LB). The outcomes additionally show that TEC variation was dominant in the vicinity of the earthquake epicentre. We also observed contrast in TEC throughout the globe using global ionospheric maps at regular 2-hour UT intervals, the day before, during and after the earthquake. As a result, we observed that areas heavily influenced by TEC were found to be transposed from eastern sectors to western sectors through the equatorial plane. TEC Maps indicate that most of the Indian regions, Northern China, Nepal, Bhutan, were heavily affected, indicating the earthquake's onset influence on the day of the event. Furthermore, we examined the cross-correlation of the SGOC station's TEC with the rest of the stations and discovered that the correlation increased gradually with epicentral distance from the surrounding stations, which was an intriguing result.

Keywords: Earthquake, Ionosphere, Total Electron Content, Seismic Waves, Ionospheric Anomaly

\section{Introduction}

The ionosphere is a complex layer in the upper atmosphere that undergoes spatial and temporal changes, mainly due to geomagnetic activity and ionisation from solar extreme ultraviolet (EUV) radiation. Usually, all energy input for ionosphere variations is predominantly attributed to solar and geomagnetic influences, while other influences have been essentially ignored (Pulinets et al., 1998). However, recent studies have shown the importance to study ionospheric disturbances for earthquake monitoring (Pulinets, 2007; Sharma et al., 2017a; Sha et al., 2020b), and significant studies have focused on ionospheric perturbations due to earthquakes (Liu et al., 2000; Pulinets, 2002; Pulinets et al., 2005; Sharma et al., 2017a; Sha et al., 2020a, 2020b). Major earthquakes are destructive and unforeseen natural phenomena where the unexpected fault rupture results in a sudden release of energy initially stored in the Earth's crust (Ohnaka, 2013). Numerous attempts have been made to predict earthquakes, and numerous measurements have been tested, such as those from Ionosonde, seismicity (Wang et al. 2010), radon and hydrogen gases (Planini et al., 2004) and energetic electron precipitation (Kudela et al., 1992). Fortunately, variations in the ionosphere have been suggested being the key parameter to detect pre-earthquakes. For instance, Jiang (2017) investigated the ionospheric total electron content (TEC) before the $2014 \mathrm{Mw} 8.2$ Chile earthquake and observed positive anomalies 4 days before the main event. TEC is the total number of electrons present along a path between two points, with units of electrons per square meter, where $10^{16}$ electrons $/ \mathrm{m}^{2}=1$ TEC unit (TECU) (Klobuchar, 1991; Adhikari et al., 2019; Silwal et al., 2021). Based on TEC observations, Global Positioning System (GPS) stations have become an important data source to study ionospheric TEC before major earthquakes. In addition, other data sources to detect TEC perturbations include, e.g., COSMOS Satellite measurements, DEMETER Satellite measurements (Pulinets, 2002; Haase, 2011; Pisa et al., 2012). The lithosphere- 
atmosphere-ionosphere coupling mechanism can eventually regulate the connection between ionospheric TEC anomalies and earthquake occurrences (Pulinets, 2004). The mechanism is thought to be reliant on changes in global electricity caused by ions accumulated during the development of stress in the crustal area prior to earthquakes (Pulinets, 2004; Friedemann and Kulahci, 2009; Sharma et al., 2017a). Pullinets (2004) suggested a detailed description of the process via ion cluster formation in the near-ground layer around the earthquake preparation zone. Although several studies have reported the TEC anomalies from 0 to 8 days before major seismic events (Pulinets, 2009; Liu et al., 2011; Sharma et al., 2017a; Sha et al., 2020a, 2020b, Parashar et al., 2018), TEC disturbances due to earthquakes are difficult to detect, primarily due to lack adequate observations and other drivers of TEC variations such as geomagnetic storms (Pullinets, 2007, 2009).

In this study, we investigate ionospheric TEC variations triggered by the $2015 \mathrm{Mw} 7.8 \mathrm{Nepal}$ Earthquake. Nepal is a seismically active region where devastating earthquakes have occurred in the past. On 25 April 2015, a large magnitude (Mw 7.8) earthquake occurred at 06:11:25 h UTC (11:56 Nepal Standard Time) with the epicentre located at $28.1473^{\circ} \mathrm{N}$ and $84.708^{\circ} \mathrm{E}$, at $8.2 \mathrm{~km}$ depth, and about $34 \mathrm{~km}$ east-southeast of Lamjung, Nepal (Adhikari et al., 2020). The main shock was followed by two large aftershocks of Mw 6.7 (on 26 April 2015 at 09:10 UTC) and Mw 7.3 (on 12 May 2015 at 07:05 UTC). This paper reports the TEC disturbances observed by GPS stations near and relatively distant from the epicentre during the April 2015 Gorkha earthquake.

\section{Data and Method}

The GPS-derived TEC data of nine stations (see Table 1) used in this work was obtained from UNAVCO, which is freely available on the website of UNAVCO (https://www.unavco.org/dai). The available data was in the RINEX (Receiver Independent Exchange) format v2.1, a standard ASCII format, which was further processed using the calibration technique of Ciraolo et al. (2007). The calibration technique of Ciraolo et al. (2007) is based on a thin shell model. The software converted the RINEX files into ASCII files, taking the TEC bias error calculations into account, eventually giving the values of VTEC throughout a day in 30-second intervals in an ASCII format. This approach assumes that the ionosphere is concentrated within a thin shell located at around 357-457 $\mathrm{km}$ of altitude (Oikonomou et al., 2016). First, the slant range TEC (STEC) was obtained from the RINEX dual-frequency carrier-phase observations $\mathrm{L}_{1}$ and $\mathrm{L}_{2}$ (Chen et al., 2017; Shi and Guo et al., 2019)

$$
\mathrm{STEC}=\frac{(f 1 f 2)^{2}}{40.3\left(f 1^{2}-f 2^{2}\right)}\left(\mathrm{L}_{1}-\mathrm{L}_{2}+\lambda_{1}\left(\mathrm{~N}_{1}+\mathrm{b}_{1}\right)-\lambda_{1}\left(\mathrm{~N}_{2}+\mathrm{b}_{2}\right)+\varepsilon_{\mathrm{L}}\right.
$$

In this equation, $\mathrm{fl}$ and $\mathrm{f} 2$ are GPS signal frequencies at $1575.42 \mathrm{MHz}$ and $1227.60 \mathrm{MHz}$; $\lambda$ is the signal wavelength; $\mathrm{N}$ is ambiguity; $\mathrm{b}$ is the instrument biases for carrier phase, and $\varepsilon$ is the 
residuals. Then, the vertical TEC can be computed from STEC with the following mapping function:

$$
\mathrm{VTEC}=\mathrm{STEC} \times \cos \left(\arcsin \left(\frac{R \cdot \sin \alpha}{R+H}\right)\right)
$$

In this equation, $\mathrm{R}$ is the Earth radius; $\alpha$ is the elevation angle of the satellite; and $\mathrm{H}$ is the height of the ionosphere, which has been taken as an altitude of $400 \mathrm{~km}$. The original GPS data from SGOC, HYDE and IISC stations are sampled at a 30s interval, and that from the other six stations (CHLM, NPGJ, KKNI, DNSG, JMSM, DNDG) at a 15s interval. We resampled all the data to $1 \mathrm{~h}$ resolution through a mean average running filter for this study. In order to identify the seismo-ionospheric disturbances, we employ the upper and lower bounds (Liu et al., 2004; Sharma et al., 2017a) from the median $(\mu)$ and standard deviation $(\sigma)$ of a 15-day running-filter:

$$
\begin{aligned}
& \text { Upper Bound }(\mathrm{UB})=\mu+1.34 \sigma \\
& \text { Lower Bound }(\mathrm{LB})=\mu-1.34 \sigma
\end{aligned}
$$

Here, positive and negative anomalies are considered when the VTEC values exceed the upper and lower bounds, respectively (Liu et al., 2009; Yao and Chen et al., 2012). The abnormal signal is considered at a confidence interval of about 82\% (Kotz and Johnson, 1982; Oikonomou et al., 2016). We identify the possible effects by analysing the disturbance storm time Dst and the planetary Ap indices to exclude perturbations due to geomagnetic activity. Then, we study the crosscorrelation between the different stations in the time domain (Usoro, 2015; Adhikari et al., 2017, 2018; Silwal et al., 2021). Cross-correlation is the standard method to estimate the degree to which two different series are correlated. This technique compares and evaluates the information between two time series of the included parameters as a function of a time lag (Finch \& Lockwood, 2007; Mannucci et al., 2008).

Figure 1 shows a network of the GPS receiver stations utilised in this study, and Table 1 provides each GPS station's location and the distance to the earthquake epicentre. Table 2 provides the reference stations' information to study the similarity pattern between the distant station (outside Nepal) through the cross-correlation technique.

Table 1: Information of the GPS stations (within Nepal) and respective distances to the epicentre of the $2015 \mathrm{Mw}=7.8 \mathrm{Nepal}$ earthquake.

\begin{tabular}{|l|ll|l|} 
GPS Station & $\begin{array}{l}\text { Geographical } \\
\text { Latitude }\left({ }^{\mathbf{0}} \mathbf{N}\right)\end{array}$ & $\begin{array}{l}\text { Geographical } \\
\text { Longitude }\left({ }^{\mathbf{0}} \mathbf{E}\right)\end{array}$ & $\begin{array}{l}\text { Distance to the } \\
\text { epicentre }(\mathbf{k m})\end{array}$ \\
\hline CHLM & 28.2072 & 85.3141 & 57.1 \\
\cline { 2 - 4 } & &
\end{tabular}




\begin{tabular}{l|l|l|l|}
\hline NPGJ & 28.1172 & 81.5953 & 307.61 \\
\hline KKNI & 27.8007 & 85.2788 & 71.9 \\
\hline$J M S M$ & 28.8053 & 83.7433 & 115.8 \\
\hline$D N G D$ & 28.7544 & 80.5818 & 409.7 \\
\hline DNSG & 28.3451 & 83.7635 & 95.6 \\
\cline { 2 - 4 } & & & \\
\hline
\end{tabular}

Table 2: Information of Reference stations

\begin{tabular}{l|l|l|l|} 
GPS Station & $\begin{array}{l}\text { Geographical } \\
\text { Latitude }\left({ }^{\mathbf{0}} \mathbf{N}\right)\end{array}$ & $\begin{array}{l}\text { Geographical } \\
\text { Longitude }\left({ }^{\circ} \mathbf{E}\right)\end{array}$ & $\begin{array}{l}\text { Distance to the } \\
\text { epicentre (km) }\end{array}$ \\
\hline HYDE & 17.4173 & 78.5579 & 1358.64 \\
\hline SGOC & 6.8921 & 79.8742 & 1148.146 \\
\hline IISC & 13.0212 & 77.5704 & \\
\hline
\end{tabular}

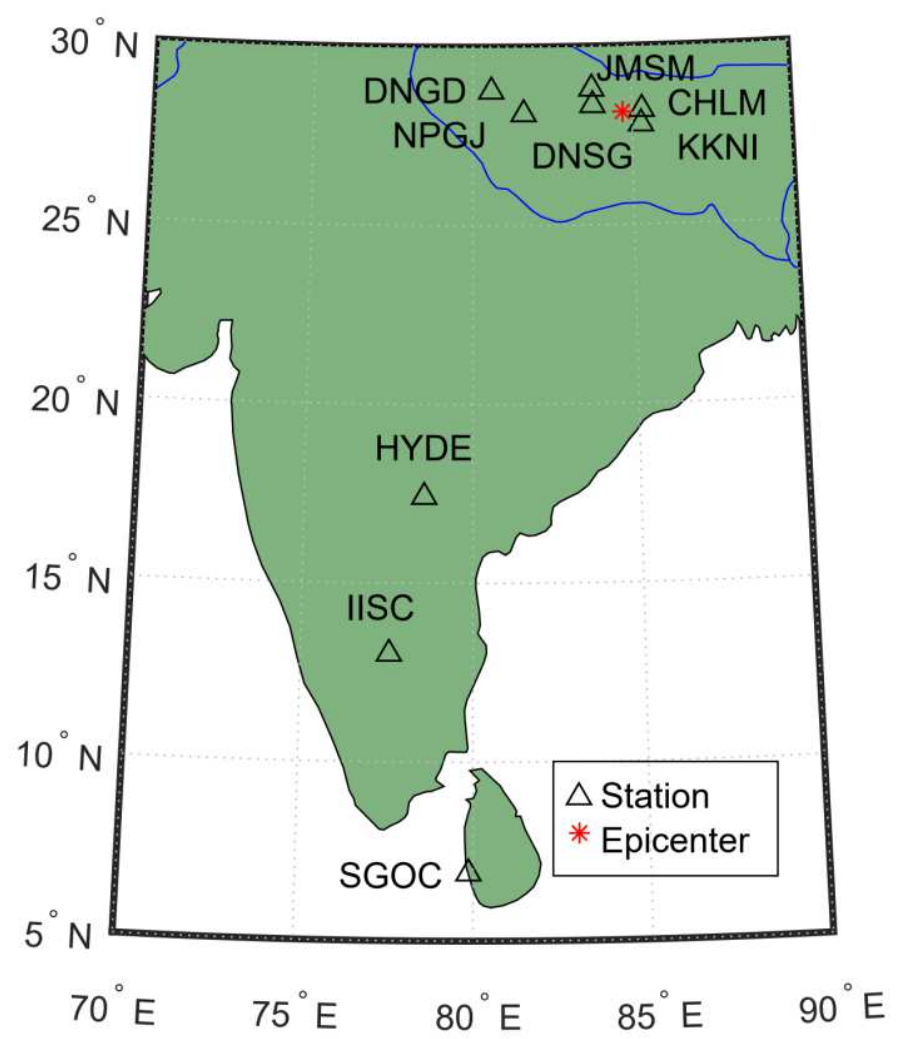

Figure 1. GPS Stations used in this study and the epicentre of the 2015 Gorkha Earthquake. 


\section{Results and Discussion}

Figure 2 shows the time series of VTEC during 25 April 2015 for the GPS stations selected for this study. In this Figure, the VTEC values and the upper bounds are plotted with respect to the lower bounds for clarity (so that the lower bounds are zero). The selected GPS stations are located up to $500 \mathrm{~km}$ radius from the epicentre of the 2015 Gorkha Earthquake. In Figure 2, we can observe several positive and negative anomalies of VTEC. For instance, a prominent positive anomaly was observed on the days $2^{\text {nd }}, 3^{\text {rd }}, 14^{\text {th }}, 16^{\text {th }}, 17^{\text {th }}$, and $24^{\text {th }}$ of April (prior to the mainshock on 25 April 2015), and negative anomalies on the days $11^{\text {th }}$ and $29^{\text {th }}$ of April at the CHLM GPS station (located at $57.1 \mathrm{~km}$ distance from the epicentre). The low TEC value observed was attributed to the reversal of electric field direction as postulated by Pulinets (1998) and Sharma et al. (2017a). In order to check the consistency of TEC anomalies, similar anomalies were expected to be observed from other stations. The analysis shows identical patterns in TEC anomalies from all six observations stations. Additionally, at other observatories GPS stations, the investigation revealed high TEC anomalies, crossing UB on the same anomaly days that we observed at CHLM station except for 29 April, including 4 April 2015 prior to the main event at DNGD located at a distance of $409.7 \mathrm{~km}$ from the epicentre. Observations at KKNI and NPGJ GPS stations located at a distance of $71.9 \mathrm{~km}$ and $307.61 \mathrm{~km}$, respectively, indicate a high TEC anomaly on $5^{\text {th }}$ and $23^{\text {rd }}$ April before the earthquake. TEC derived from DNSG and JMSM located at a distance of $95.6 \mathrm{~km}$ and $115.8 \mathrm{~km}$, respectively, showed similar anomalies like other stations. In addition to the mainshock on 25 April 2015 , it was followed by big aftershocks on the same day as well as on 26 April with a magnitude of 6.7 at around 12:54:08 NST (07:08 UTC), with an epicentre located about $17 \mathrm{~km}$ south of Kodari, Nepal (USGS earthquake catalogue). These anomalies were also checked with other geomagnetic indices (Dst, Ap) and solar flux, F10.7, to detect the effect of a geomagnetic storm, as shown in Figure 3. It was observed that these anomalies were not affected by any geomagnetic phenomenon except for $16^{\text {th }}$ and $17^{\text {th }}$ of April. The change in TEC depends on solar activity, geomagnetic storms and receiving GPS station location and also varies with time and space. The energy and currents released by a geomagnetic storm increase the total height-integrated number of ionospheric TEC (Sharma et al., 2017a). An increase in ionospheric TEC results in the spatial variability of the ionosphere and cause ionospheric delays in the GPS signals (Pulinets, 2009). Overall, the TEC values corresponding to the anomaly time from all six stations was observed that the earthquakes had at least one high TEC value crossing UBL and low TEC value crossing LBL, which was also observed in earlier studies (Sharma et al., 2017a, 2019, 2020). 


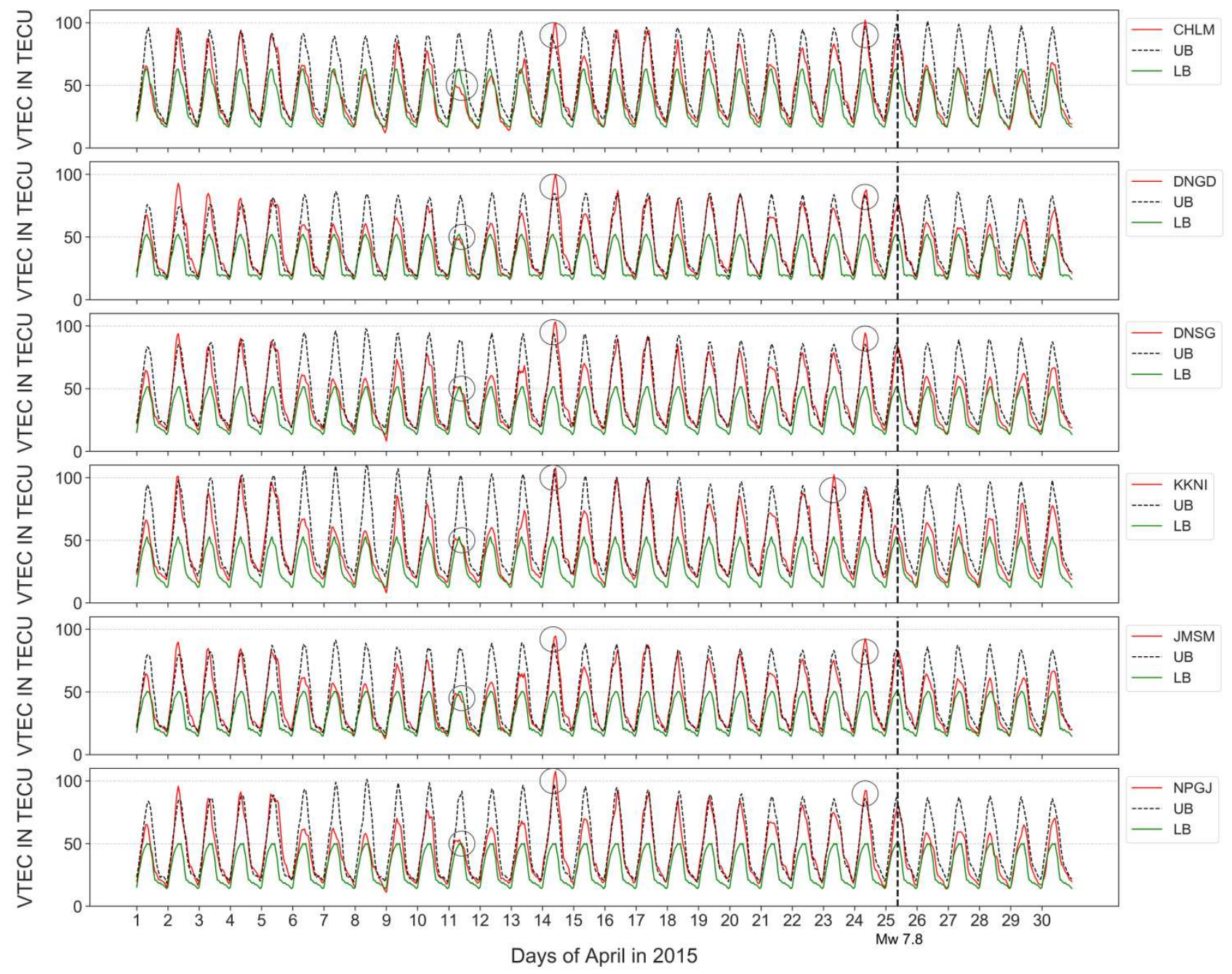

Figure 2. Six different GPS stations of Nepal are used to analyse TEC variations. The red line represents daily TEC values from different stations, while black dotted lines and solid green lines are for upper and lower bounds. Earthquake day is represented by a vertical dashed line with the heading of all GPS stations. 

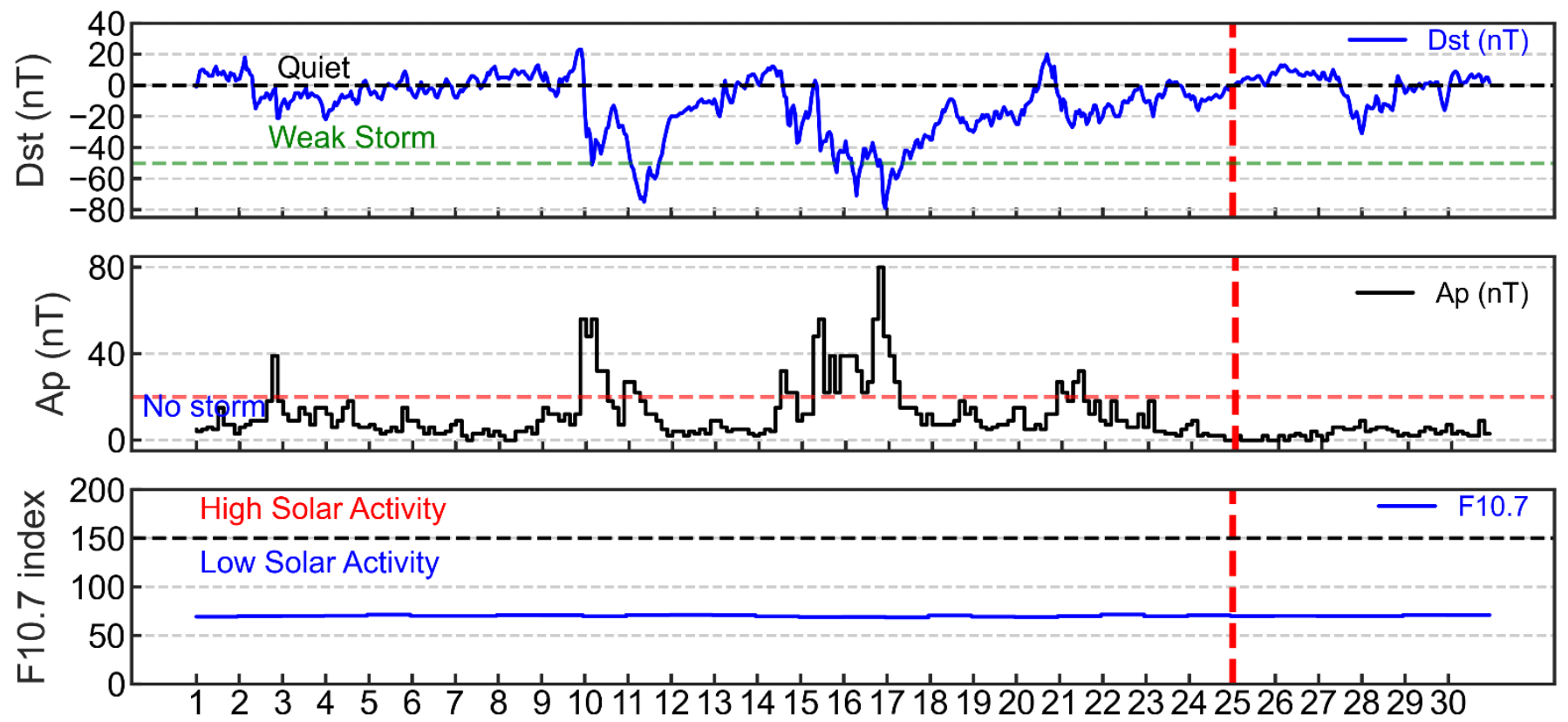

Days of April in 2015

Figure 3. Geomagnetic storm conditions from Dst, Ap and Solar flux, F10.7 for the entire month of April 2015. The red dashed line represents Earthquake Day.

Figure 4 shows the variation of TEC level during the earthquake event of 25 April 2015 compared to the mean TEC of the top five quietest days of the month at DNGD, DNSG, JMSM, KKNI, NPGJ and CHLM stations. All stations follow the diurnal variation of VTEC with a minimum at $\sim 0 \mathrm{~h}$ UTC and a maximum at $\sim 8 \mathrm{~h}$ UTC. The value of VTEC during "earthquake day" is exceeding the "quiet day" during few hours before the event. Then, a significant TEC increment can be seen during the earthquake time, reaching a maximum at $\sim 8 \mathrm{~h}$ UT (13:45 LT). High deviation remained for about 7 hours after the mainshock (up to 14:00 UT). 


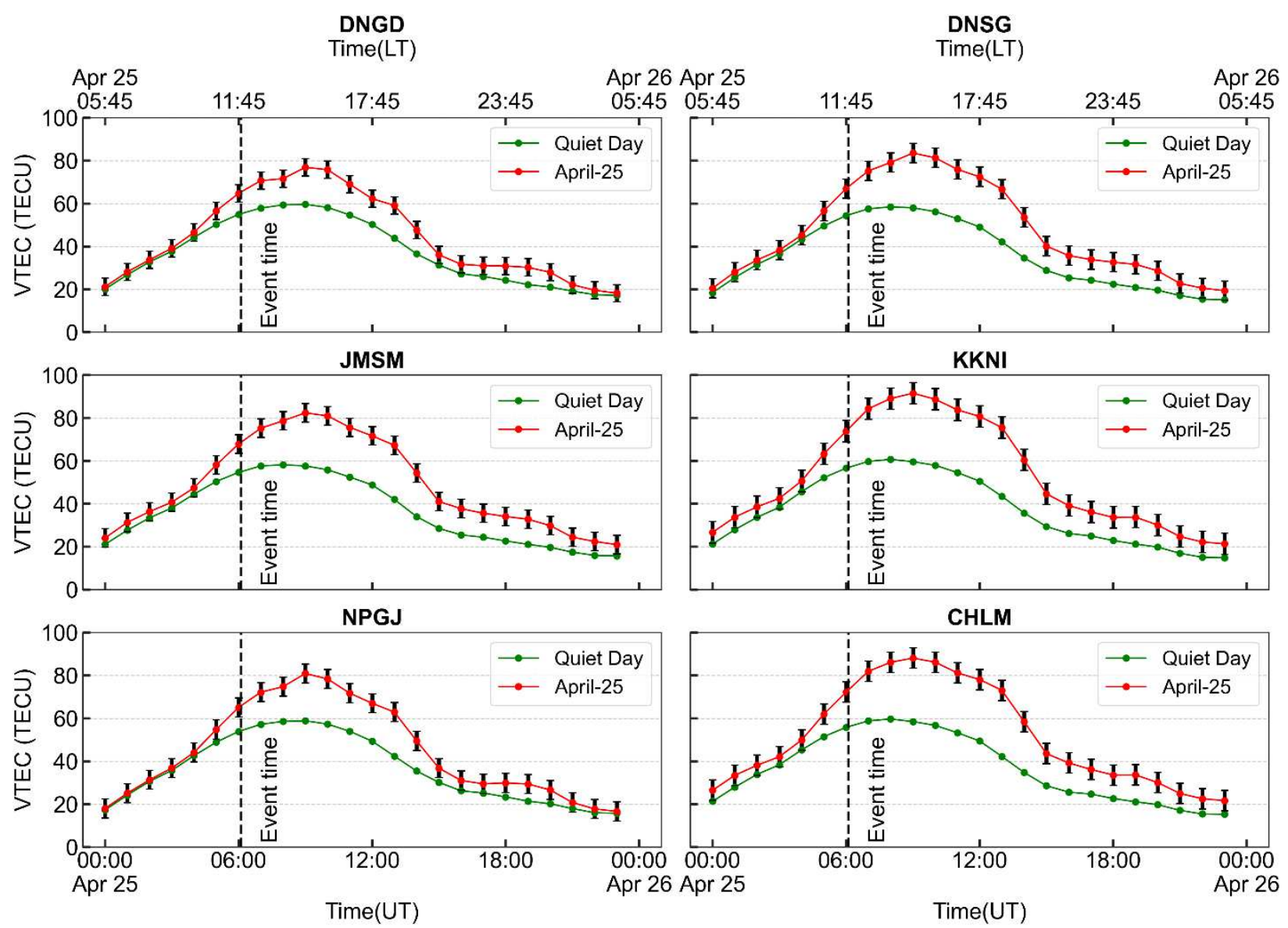

Figure 4. Comparison of TEC at six different stations of Nepal during the 2015 Gorkha Earthquake and with the mean values of top five quietest days of the month, April 2015. The vertical bar represents the standard error.

Figure 5 shows the deviation of VTEC from the mean value of the top five quietest days of the month, April 2015, in terms of percentage. As observed from the DNGD GPS station, the maximum VTEC difference between the earthquake and the quiet days reached 17 TECU, whereas 25 TECU for DNSG and JMSM stations, 32 TECU for KKNI, 30 TECU for CHLM, and 22 TECU for NPGJ positive deviations of VTEC. The deviations seem to decrease proportionally to the distance to the epicentre. This hypothesis has been presented in earlier studies (Sharma et al., 2017a). For example, the DNGD station (located at about $\sim 409 \mathrm{~km}$ from the epicentre) showed a deviation of 17 TECU, whereas 32 TECU was spotted from the KKNI station $(71.9 \mathrm{~km}$ from the epicentre). Thus, the deviation of VTEC from quiet days fairly relates with distance to the epicentre.

Figure 4 depicts a significant increase in VTEC value during the earthquake event day compared to the quiet day. In this section, we study the deviation of GPS derived mean hourly VTEC in terms of percentage during the earthquake event day, i.e., 25 April 2015, from the mean of the top 5 quietest days of the same month. The World Data Centre provided the data of the top five quietest days for Geomagnetism, Kyoto (http://wdc.kugi.kyoto-u.ac.jp/qddays/). Figure 4 describes a high deviation 
in TEC right after the mainshock of earthquake event, which was observed at 6:11 UT ( 11:56 LT), and the almost constant increment remained for about 7 hours after the mainshock, i.e., up to 14:00 UT. As observed from the DNGD GPS station, the maximum VTEC difference between the day of the earthquake and the quiet day reached 17 TECU whereas 25 TECU from DNSG and JMSM stations, around 32 TECU while observed from KKNI, 30 TECU from CHLM and 22 TECU from NPGJ GPS stations. The high deviation of VTEC on event day from the quiet day was observed during the time interval of 6:00 UT to 14:00 UT. However, there was a relatively small deviation $<10 \%$ before the mainshock and after 7 hours of the mainshock, i.e., after 14:00 UT in all stations, as witnessed from Figure 4. It is noteworthy that, throughout the earthquake event day, the positive deviation of VTEC was recorded.

It was also noticed that the deviation decreased with an increase in distance from the epicentre. The DNGD station, which is $409 \mathrm{~km}$ from the epicentre, showed a maximum deviation of only 17 TECU, whereas a deviation up to 32 TECU was spotted from the KKNI GPS station, which is only $71.9 \mathrm{~km}$ away from the epicentre. TEC variation is found to increase as the epicentre distance decreases, which was also supported in earlier studies (Sharma et al., 2017a). The deviation of VTEC from quiet days fairly relates to the distance (see table 1) of the station from the earthquake's epicentre. Since earthquake event day was also the geomagnetically quiet day, increment in VTEC during and after the earthquake event compared to other quiet days disclosed a momentous relation between seismic activity like earthquake and the ionospheric TEC.

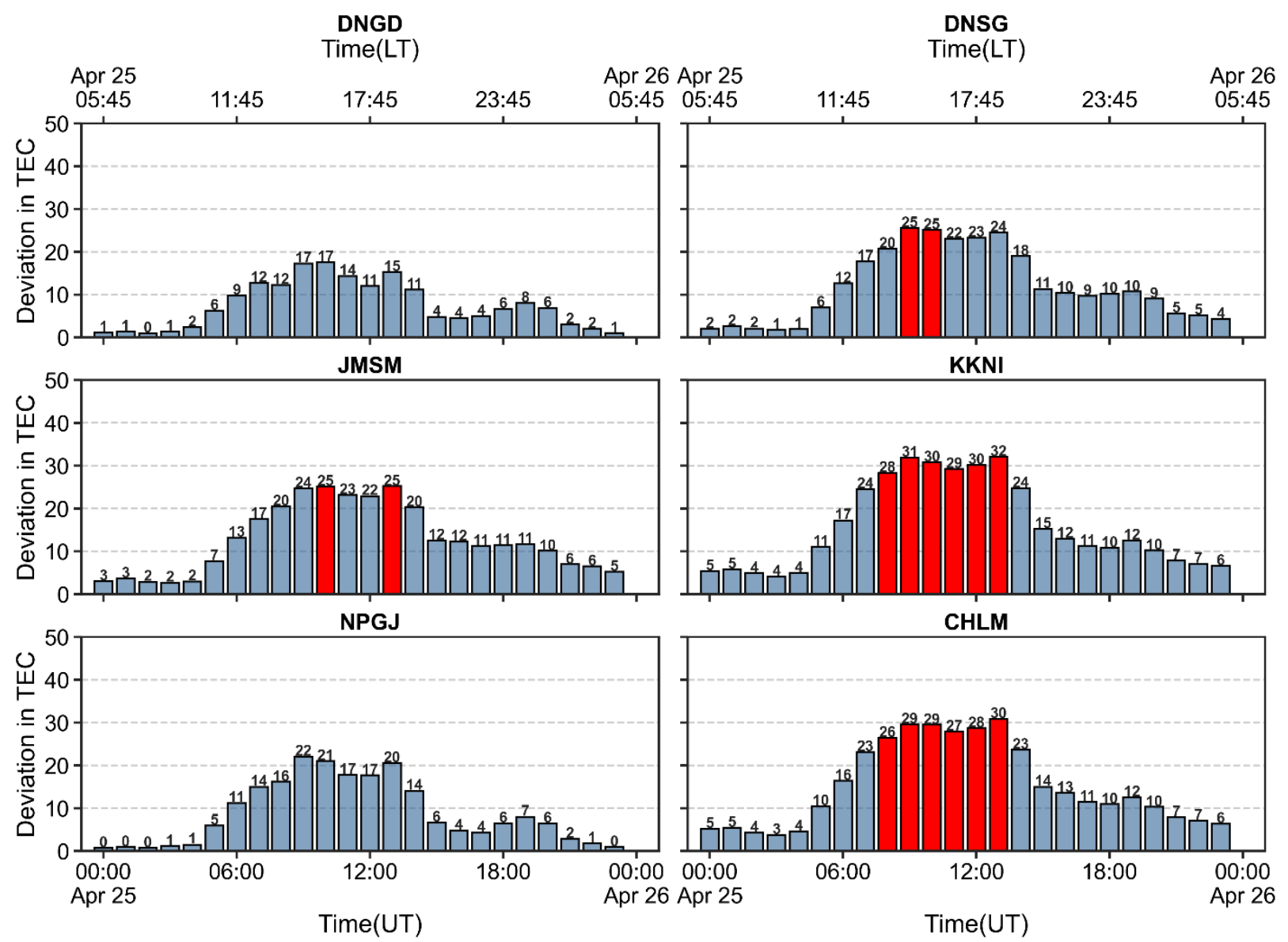


Figure 5. Deviation of VTEC during the 2015 Gorkha Earthquake with respect to the mean values of 5 days with quiet geomagnetic activity. The red bars represent a high deviation in TEC values $(\geq$ 25 TECU).

\section{Cross-Correlation Analysis}

Figure 6a shows the cross-correlation of the hourly mean VTEC between the DNGD station and the other- stations during the 2015 Gorkha Earthquake. Time scales help understand the lead or lag between the data after establishing their correlation (Adhikari et al., 2018; Poudel et al., 2021). Figure displays cross-correlation coefficient +1 at a zero-time lag. Figure $6 \mathrm{~b}$ shows the correlation between mean values during the quiet days to the distant -SGOC, IISC, and HYDE stations. We can see that during the quiet day, similar variation occurs between mid and low latitude regions, independently of the latitudinal locations.
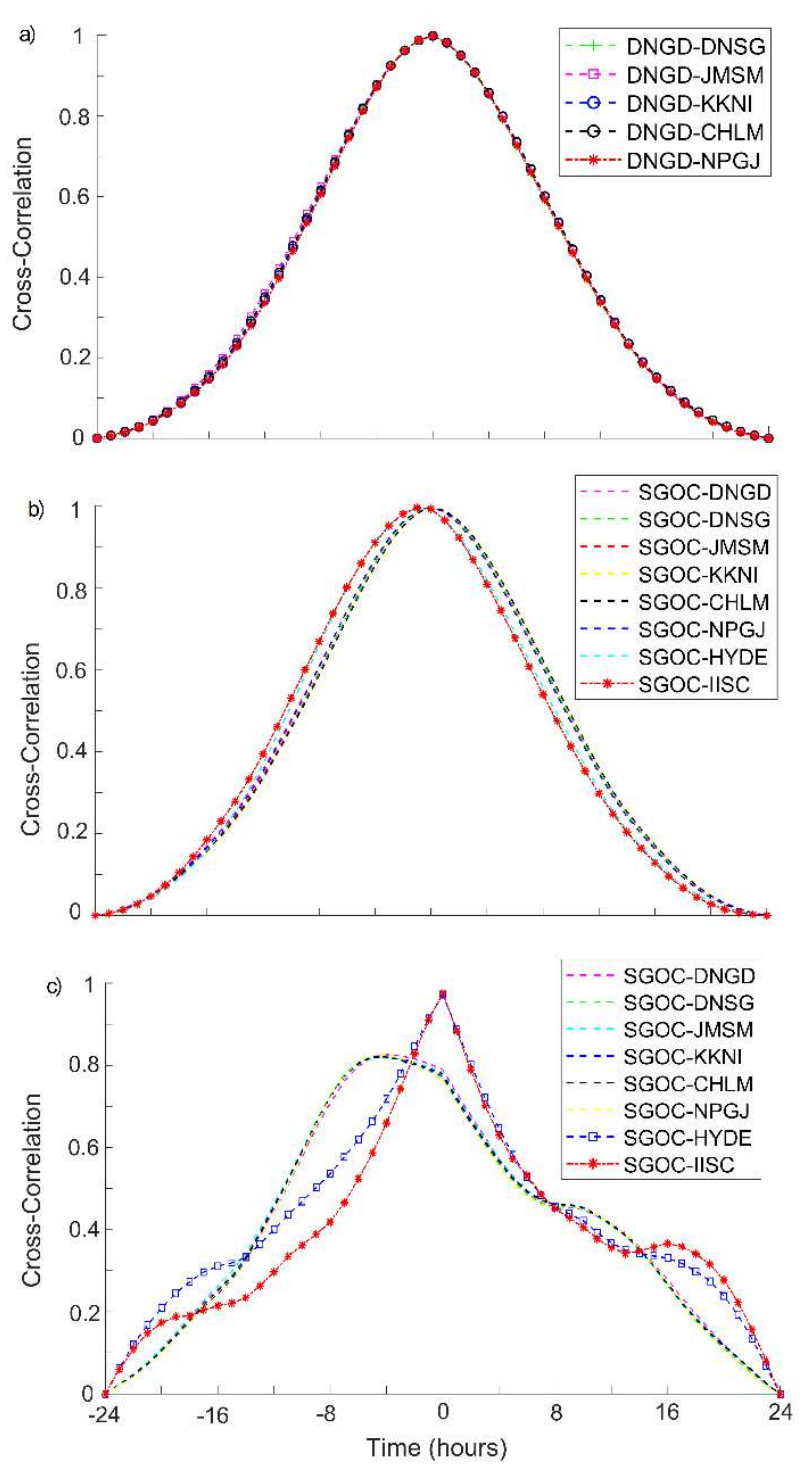

On the other side, Figure (6c) shows the cross-correlation of the SGOC station with the other stations during the day of the earthquake, showing a time lag of about 5 hrs between distant and nearby stations to the epicentre. SGOC, IISC and HYDE stations were strongly correlated during the earthquake event day, while the other stations show less correlation with $5 \mathrm{hrs}$ lag. The results obtained from the crosscorrelation analysis supports that the increase in TEC value reported in the above section was solely due to the Earthquake event. 
Figure 6. (a) Cross-correlation of VTEC derived from DNGD station with the other stations during the 2015 Gorkha Earthquake, (b) Cross-correlation between SGOC station and the mean values quiet days from the other stations and (c) Cross-correlation between SGOC station and the other stations during the 2015 Gorkha Earthquake.

In Figure 6, no noticeable lag has been found between stations nearby the epicentre. On earthquake event day, the GPS TEC response to the seismic activity is relatively rapid, as reflected by a zerotime lag value. All the stations affected by earthquake show a similar change in the global electric circuit, produced by gathering ions in the atmosphere originating from the stress in the crustal region prior to an earthquake (Pulinets, 2004; Friedemann and Kulahci, 2009). On the other hand, the decreased cross-correlation coefficient with a low time lag value between the stations, which are not affected by the earthquake, accounts for the fewer perturbations on the ionospheric TEC during the event day. This indicates that the findings obtained are encouraging because, in future days, the space weather associated with the earthquake's impact can easily be predicted by precise measurements of lead or lag in the response of the GPS TEC linked with seismic events.

\section{Global Ionosphere Map}

Figures 7,8 and 9 define the contrast across the globe in TEC at a daily 2-hour UT interval on the day before, during and after the 201525 April Earthquake. The contour, along with the colour gradient, represents the global TEC intensity. The high to low TEC activity ratio can be compared at any spatiotemporal location to assess changes in the ionosphere that are evolved during the day. Figures reveal ionospheric maps based on geographical longitude and latitude over a global scale, produced using various GPS-TPS stations in Nepal. The global contour plot indicates a transition in TEC with a gap of 2 hours beginning at 00:00 UT. The equatorial area comprises optimum spatial and temporal variations of the TEC and includes various ionosphere characteristics, including the anomaly of the equatorial system and scintillation. Thus, the emphasis is on the band of latitudes $26^{\circ}-31^{\circ} \mathrm{N}$, and longitudes $80^{\circ}-89^{\circ} \mathrm{E}$.
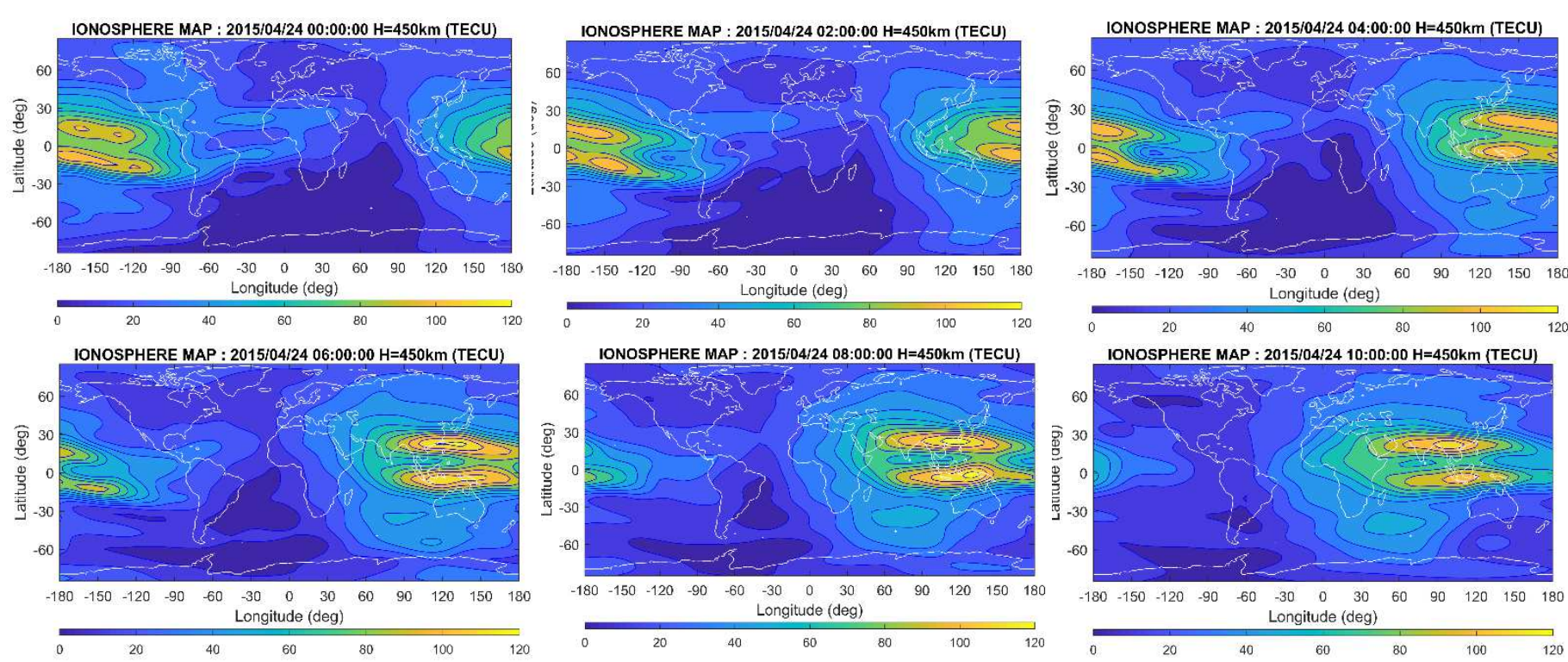

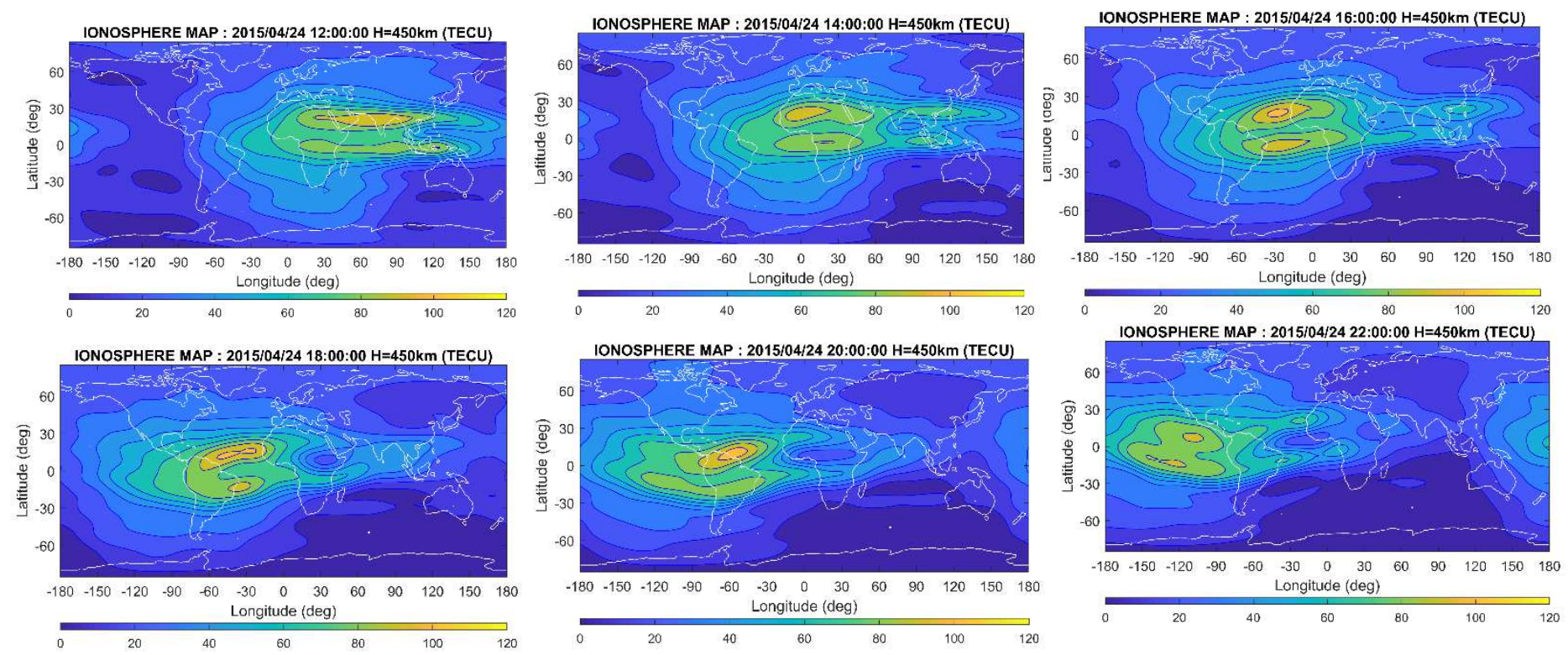

Figure 7. Global GPS-TEC maps on 24 April 2015 at a regular interval of 2 hours in UT.

At 00:00 UT-02:00 UT on 24 April, TEC content is high across the Pacific Ocean relative to other parts of the map. At 04:00 UT, the mild intensification of TEC, as initially seen, spreads to Indonesia, New Guinea and the Philippines and becomes intense at 06:00 UT. The Vietnam, Singapore and Southern China sectors are showing substantial TEC relative to the others. At 08:00 UT, there is a slight increase in TEC in the Eastern African region. From 08:00 UT-10:00 UT, the main concentration of TEC is located at lower latitudes $\left(-30^{\circ} \mathrm{S}\right.$ to $\left.-30^{\circ} \mathrm{N}\right)$ between the regions of Indian and Southern China and is slowly moving towards Eastern Africa via the Arabian Sea. From 12:00 UT to 14:00 UT, TEC concentration is lower than the previous few hours and mild intensification of TEC is seen over Northern Africa. At 14:00 UT, TEC concentration shifts towards the South American region via the Northern Atlantic Ocean from Africa. TEC is more pronounced towards the Atlantic at 16:00 UT and more pronounced over the western regions of Africa between 16:00 UT and 20:00 UT. There is a comparatively high TEC accumulation over the low Latitude Atlantic regions $\left(0^{\circ}-20^{\circ} \mathrm{N}\right)$ at 18:00 UT. From 20:00 UT-22:00 UT, South America's lower latitudinal regions exhibit extreme TEC. After 22:00 UT, TEC value decreases until the early hours of 25 April between $-30^{\circ}$ to $30^{\circ}$ latitude across the Pacific Ocean, indicated by dark yellow colour. On 24 April, the most extreme TEC fluctuation is observed between 8 UT-10 UT over most of China and India's lower latitudinal area, while North American regions and Australian sectors display minimum TEC concentration throughout the day.
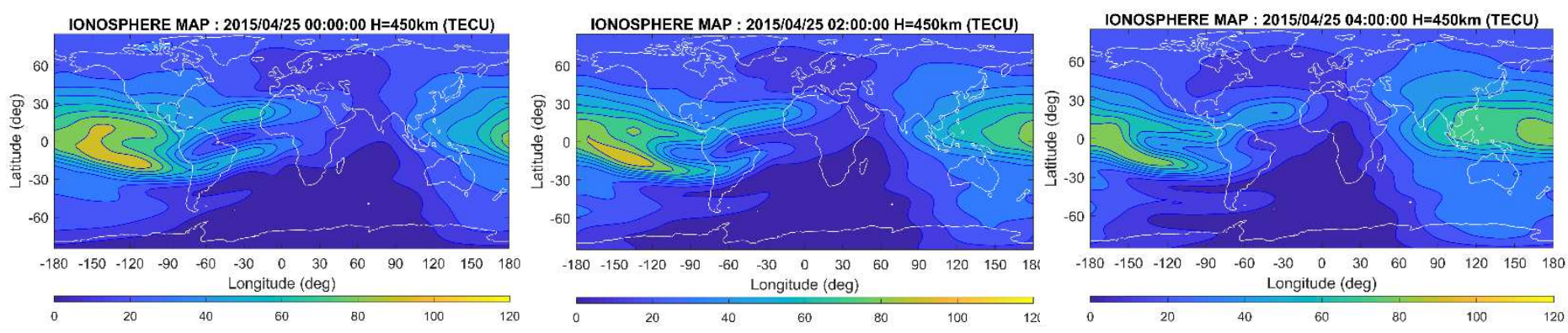

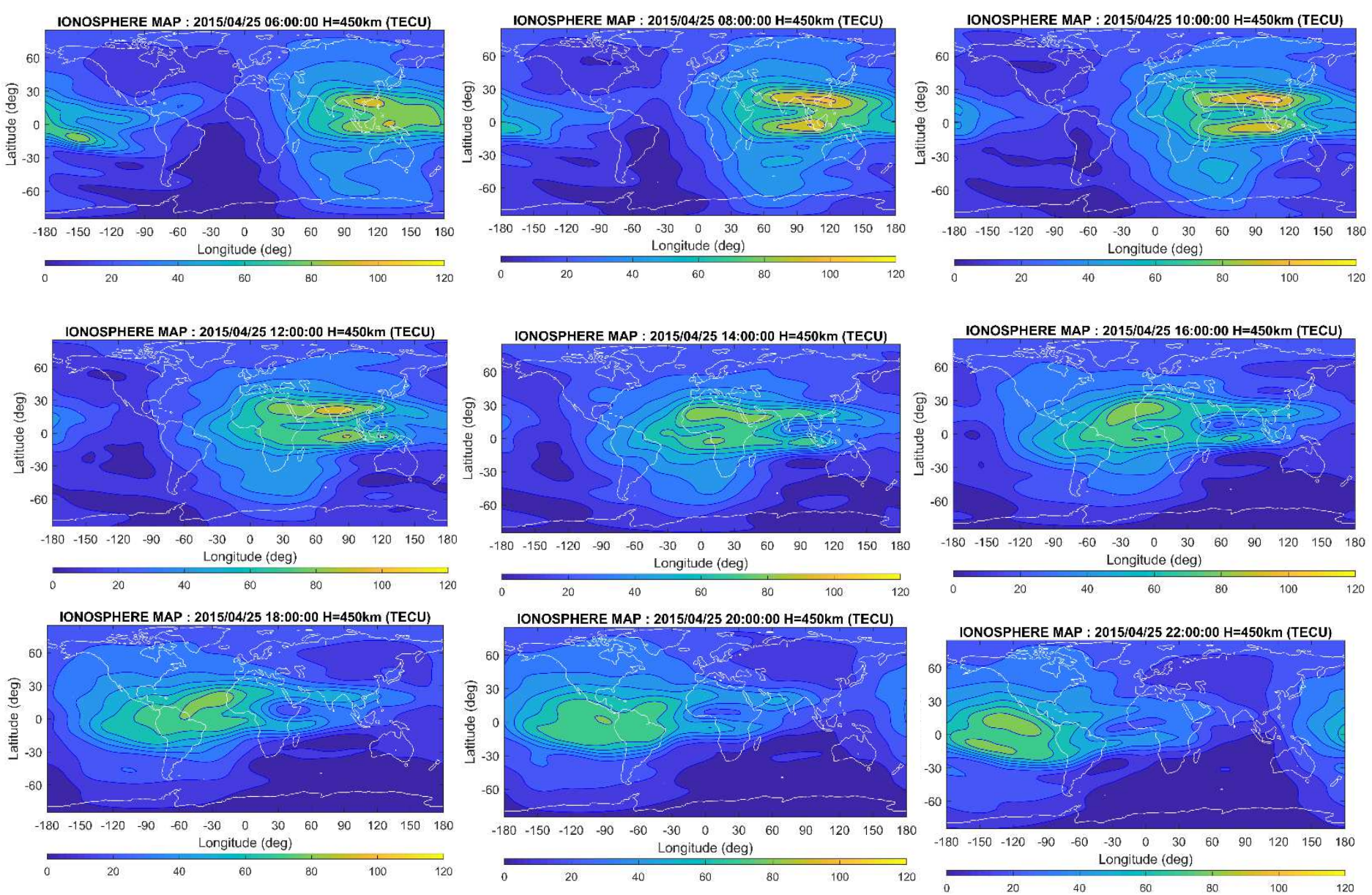

Figure 8. Global GPS-TEC maps on 25 April 2015 at a regular interval of 2 hours in UT.

At 00:00 UT - 02:00 UT on 25 April, TEC content is supplementary over the northern Pacific and Atlantic Ocean (40-60 TECU). At 04:00 UT, TEC concentration begins to intensify over the East China Sea, Indian region, Bay of Bengal, Indonesia and Malaysia and turns out to be extreme at 06:00 UT. At this point, compared to other parts of the globe, the Eastern China and Northern New Guinea regions display significant TECs. From 08:00 UT - 10:00 UT, TEC concentration rises significantly compared to the previous few hours in most of the Indian areas, Northern China, Nepal, Bhutan and the Indian Ocean (100-120 TECU), and by the end of 10:00 UT, the TEC concentration is observed to be shifting towards the Eastern and Central Africa. At 12:00 UT, lower latitudinal regions of Africa and India evinces mild TEC over the region. This intensification lasts until 18:00 UT over Western African regions and the North Atlantic Ocean until 14:00 UT over northern African regions. From 20:00 UT-22:00 UT, the North-West regions of South America had a moderate TEC over the area relative to the preceding hours. After 22:00 UT, TEC value decreases until the early hours of 26 April between $-30^{\circ}$ to $30^{\circ}$ latitude across the Pacific Ocean indicated by dark yellow colour Between the period of 06:00 UT - 12:00 UT; TEC concentration is remarkably 
high near to the regions of Nepal ranging from 100-120 TECU, which continues until the end of the day through the equatorial plane covering low latitudinal regions.
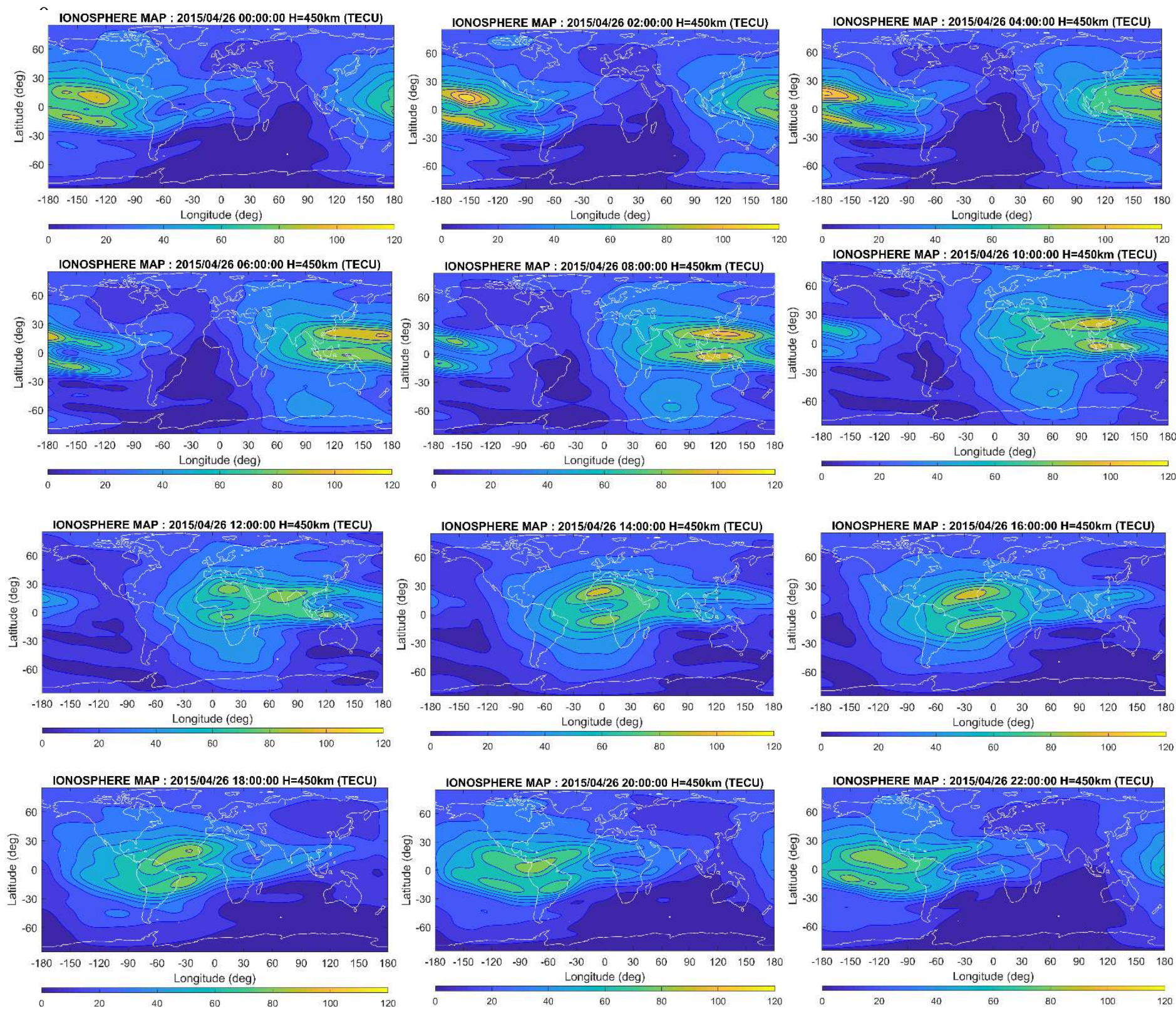

Figure 9. Global GPS-TEC maps on 25 April 2015 at a regular interval of 2 hours in UT.

Following the earthquake day, the Equatorial and Low Latitude regions are observed in the Pacific Ocean with increased TECs while the Indian belts show minimum effects. Mild TEC variation is observed near Northern Australia, Guinea, Indonesia and East China at 06:00 UT. At 08:00 UT on 26 April, highly amplified TEC effects are seen across southern China and near Indonesia, including parts of Malaysia and the Indian regions, depicted by a dark yellow colour. Soon, the TEC variations get prolonged over India, Nepal, and China and Eastern African zones at 10:00 UT nearequatorial planes. The TEC concentration is diminished over the Indian, Southern China, including most African regions at 12:00 UT, following adverse impacts on African and Indian belts. From 
14:00 UT-18:00 UT, the lower part of South America displays extreme TEC over the northern African regions $\left(0-30^{\circ} \mathrm{N}\right)$, which stretch along the Atlantic Ocean. From 20:00 UT to the early morning hours of 27 April, the TEC concentration decreased across the northern sector of South America along with the North Pacific Ocean. The most intense TEC is observed at 08:00 UT on 26 April, which remained between-30 ${ }^{\circ}$ to $30^{\circ}$ latitude at 10:00 UT across the Indian and Southern China regions, indicated by light yellow colour.

\section{Conclusions}

We have attempted to investigate TEC variations during the 2015 Gorkha earthquake, observed by widely distributed GPS receivers in Nepal. Following conclusions are made from the present work:

1) The 2015 Gorkha Earthquake with magnitude 7.8 was preceded by TEC anomalies as observed at a station closer to the epicentre $(57 \mathrm{~km})$ and three GPS stations at a distance of $(1000-2570 \mathrm{~km})$ from the epicentre. The most apparent anomaly was observed on $14^{\text {th }}$ and $24^{\text {th }}$ April 2015 (one day before mainshock), although the earliest abnormality was observed on 11 April 2015, which was also observed in earlier studies (Sharma et al., 2017a, 2019, 2020).

2) By analysing the data of geomagnetic indices for the same observation period, we observed no geomagnetic storm before and after the earthquake. Thus, we can conclude that the TEC variations as observed were attributed due to seismogenic causes.

3) The analysis of deviation in VTEC on earthquake event day (also a geomagnetically quiet day) from the mean VTEC of the top four quietest days showed that there was an abrupt rise in the value of GPS VTEC after the earthquake event relative to that of the quiet geomagnetic days and the high deviation persisted approximately 7 hours after the earthquake occurred.

4) The less deviation of VTEC observed on the GPS station far from the epicentre than that of stations nearby suggests a high increment in VTEC near the epicentre, and variation in ionospheric VTEC almost inversely depends upon the distance of GPS stations from the epicentre. As the intensity of the earthquake decreases with distance from the epicentre, this spatial variation of VTEC can also be summarised as the outgrowth of ionospheric TEC perturbations with the intensity of the earthquake. 
5) The cross-correlation between GPS derived VTEC on earthquake event day within stations of earthquake affected region (of Nepal) showed a strong correlation of VTEC with coefficient +1 at a zero-time lag. Similarly, the cross-correlation study of VTEC on a quiet day among the stations of mid-latitude and lower latitudes (includes earthquake affected and unaffected stations) also showed a strong positive correlation with a peak at +1 at phase. On the other hand, during the earthquake event day, instead of taking the same GPS stations for cross-correlation study, we only observed a strong positive association between VTEC derived from stations that were not affected by the earthquake (SGOC, IISC, HYDE) with a correlation coefficient of +1 at phase. In contrast, all cross-correlation curves between VTEC derived from earthquake-affected and unaffected GPS stations displayed a peak at 0.8 with a certain time-lag indicating less correlation between VTEC from earthquake-affected and unaffected regions. Overall, cross-correlation findings have concluded that the increase in VTEC value in the earthquake event day relative to the quiet day is due to the seismic waves produced by the earthquake.

6) TEC Maps evince that most of the Indian regions, Southern China, Nepal regions were affected heavily, explaining the effect of the earthquake. There were no significant fluctuations a day before and after the earthquake. All the Nepalese stations attain their highest TEC values during the event. When observed at Global Ionospheric Maps, TEC prolongs towards lower or mid-latitudinal region (30 to -30 degrees) through the equatorial plane during the event.

As these naturally occurring phenomena overwhelm the Earth, we have observed abrupt modifications in ionospheric TEC data detected in different monitoring stations. By integrating measurements based on the global impact of such natural events, we can monitor the response of TEC towards the seismic events, and it could be used as a suitable tool to forecast the possible seismic activity. Pulinets (1998) also concluded ionosphere-seismic consequences are an ongoing process and are a key cause of ionosphere variability, and such consequences may be seen at least five days before an earthquake and can be used to predict a near-future earthquake in a region.

\section{Author's Contribution}

Monika Karki: Conceptualization, Methodology Implication, Visualization, Writing- Original draft preparation; Ashok Silwal: Conceptualization, Software, Data curation, Visualization, Formal Analysis, Writing- Original draft preparation; Narayan Prasad Chapagain and Binod Adhikari: Supervision, Project Administration, Formal Analysis, Validation, Resources; Sujan Prasad Gautam: Conceptualization, Methodology Implication, Writing- Original draft preparation; 
Prakash Poudel: Validation, Methodology, Writing- Original draft preparation; Ranjan Kumar Dahal: Writing- Reviewing and Editing, Validation; Basu Dev Ghimire and Roshan Kumar Mishra: Writing- Reviewing and Editing; Yenca Migoya Orue: Writing- Reviewing and Editing, Validation, Supervision; Andres Calabia: Writing- Reviewing and Editing, Validation, Supervision.

\section{Acknowledgements}

Geomagnetic indices (Ap and Dst) data were obtained from the ISGI service (http://isgi.unistra.fr/geomagnetic indices.php). Solar flux, F10.7 data were downloaded from the OMNI web service (https://omniweb.gsfc.nasa.gov/). In addition, GPS RINEX data were extracted from the UNAVCO Data Archive (https://www.unavco.org/data/dai/) for the stations mentioned in Table 1. We want to thank NASA and UNAVCO for making the data available.

Data availability: All the datasets used for this work can be received upon request to the corresponding author.

Conflict of Interest: The authors declare that they have no conflict of interest.

Funding: This research work was granted with MSc dissertation fellowship from University Grant Commission (UGC), Nepal.

Ethical approval: Not applicable.

\section{References}

Adhikari, B., Adhikari, R., Chapagain, N. P., Sapkota, N., Dahal, S., \& Pandit, D. (2017). Daily, seasonal and monthly variation of middle-low latitudes magnetic field during low solar activity. Discovery, 53(255), 181-190.

Adhikari, B., Dahal, S., Karki, M., Mishra, R. K., Dahal, R. K., Sasmal, S., \& Klausner, V. (2020). Application of wavelet for seismic wave analysis in Kathmandu Valley after the 2015 Gorkha earthquake, Nepal. Geoenvironmental Disasters, 7(1), 1-16.

Adhikari, B., Dahal, S., Sapkota, N., Baruwal, P., Bhattarai, B., Khanal, K., \& Chapagain, N. P. (2018). Field-Aligned Current and Polar Cap Potential and Geomagnetic Disturbances: A Review of Cross-Correlation Analysis. Earth and Space Science, 5(9), 440-455.

Adhikari, B., Kaphle, B., Adhikari, N., Limbu, S., Sunar, A., Mishra, R. K., \& Adhikari, S. (2019). Analysis of cosmic ray, solar wind energies, components of Earth's magnetic field, and ionospheric total electron content during solar superstorm of November 18-22, 2003. SN Applied Sciences, 1(5), 453.

Chen, P., Yao, Y., \& Yao, W. (2017). On the coseismic ionospheric disturbances after the Nepal Mw7. 8 earthquakes on 25 April, 2015 using GPS observations. Advances in Space Research, 59(1), 103-113. 
Ciraolo, L., Azpilicueta, F., Brunini, C., Meza, A., \& Radicella, S. M. (2007). Calibration errors on experimental slant total electron content (TEC) determined with GPS. Journal of Geodesy, 81(2), 111-120.

Finch, I., \& Lockwood, M. (2007). Solar wind-magnetosphere coupling functions on timescales of 1 day to 1 year. In Annales Geophysicae, 25(2), 495-506. https://doi.org/10.5194/angeo-25-495$\underline{2007}$

Freund, F. T., Kulahci, I. G., Cyr, G., Ling, J., Winnick, M., Tregloan-Reed, J., \& Freund, M. M. (2009). Air ionisation at rock surfaces and pre-earthquake signals. Journal of Atmospheric and Solar-Terrestrial Physics, 71(17-18), 1824-1834.

Haase, J.S., Dautermann, T., Taylor, M. J., Chapagain, N., Calais, E., Pautet, D., (2011). Propagation of plasma bubbles observed in Brazil from GPS and airglow data. Advances in Space Research, 47(10), 1758-1776.

Jiang, W., Ma, Y., Zhou, X., Li, Z., An, X., \& Wang, K. (2017). Analysis of ionospheric vertical total electron content before the 1 April 2014 Mw 8.2 Chile earthquake. Journal of Seismology, 21(6), 1599-1612.

Klobuchar, J. A. (1991). Ionospheric Effects on GPS, Early Innovation columns, GPS World, 1991. Available: http://gauss.gge.unb.ca/gpsworld/EarlyInnovationColumns/Innov.1991.04.pdf.

Kotz, S., Johnson, H. L., Read, C. B., 1982, Encyclopedia of statistical sciences, 519.5, E5.

Kudela, K., Matisin, J., Shuiskaya, F. K., Akentieva, O. S., Romantsova, T. V., \& Venkatesan, D. (1992). Inner zone electron peaks observed by the "Active" satellite. Journal of Geophysical Research: Space Physics, 97(A6), 8681-8683.

Liu, J. Y., Chen, Y. I., Chen, C. H., Liu, C. Y., Chen, C. Y., Nishihashi, M., \& Lin, C. H. (2009). Seismoionospheric GPS total electron content anomalies observed before the 12 May 2008 Mw7. 9 Wenchuan earthquake. Journal of Geophysical Research: Space Physics, 114(A4).

Liu, J. Y., Chen, Y. I., Pulinets, S. A., Tsai, Y. B., \& Chuo, Y. J. (2000). Seismo-ionospheric signatures prior to $\mathrm{M} \geq 6.0$ Taiwan earthquakes. Geophysical research letters, 27(19), 3113-3116.

Liu, J. Y., Chuo, Y. J., Shan, S. J., Tsai, Y. B., Chen, Y. I., Pulinets, S. A., \& Yu, S. B. (2004). Preearthquake ionospheric anomalies registered by continuous GPS TEC measurements. In Annales Geophysicae, 22(5), 1585-1593.

Liu, J. Y., Le, H., Chen, Y. I., Chen, C. H., Liu, L., Wan, W., ... \& Chen, M. Q. (2011). Observations and simulations of seismoionospheric GPS total electron content anomalies before the 12 January 2010 M7 Haiti earthquake. Journal of Geophysical Research: Space Physics, 116(A4). 
Mannucci, A. J., Tsurutani, B. T., Abdu, M. A., Gonzalez, W. D., Komjathy, A., Echer, E., ... \& Anderson, D. (2008). Superposed epoch analysis of the dayside ionospheric response to four intense geomagnetic storms. Journal of Geophysical Research: Space Physics, 113(A3).

Ohnaka, M. (2013). The physics of rock failure and earthquakes. Cambridge University Press, M04 11.

Oikonomou, C., Haralambous, H., \& Muslim, B. (2016). Investigation of ionospheric TEC precursors related to the M7. 8 Nepal and M8. 3 Chile earthquakes in 2015 based on spectral and statistical analysis. Natural Hazards, 83(1), 97-116.

Parashar, D., Sudeep, A., More, A., Patil, P., Walimbe, A., Mavale, M., \& Amdekar, S. (2018). Total electron content and epicentral distance of $2015 \mathrm{Mw} 7.8$ Nepal earthquake revealed by continuous observations data. current science, $115(1), 27$.

Píša, D., Němec, F., Parrot, M. and Santolík, O. (2012). Attenuation of electromagnetic waves at the frequency $1.7 \mathrm{kHz}$ in the upper ionosphere observed by the DEMETER satellite in the vicinity of earthquakes. Annals of geophysics, 55(1), 157-163.

Planinić, J., Radolić, V., \& Vuković, B. (2004). Radon as an earthquake precursor. Nuclear Instruments and Methods in Physics Research Section A: Accelerators, Spectrometers, Detectors and Associated Equipment, 530(3), 568-574.

Poudel, P., Parajuli, N., Gautam, A., Sapkota, D., Adhikari, H., Adhikari, B., et al. (2020). Wavelet and cross-correlation analysis of relativistic electron flux with sunspot number, solar flux, and solar wind parameters. Journal of Nepal Physical Society, 6(2), 104-112. https:// doi.org/10.3126/jnphyssoc.v6i2.34865

Pulinets, S. A. (1998). Seismic activity as a source of the ionospheric variability. Advances in Space Research, 22(6), 903-906.

Pulinets, S. A. (2007). Natural radioactivity, earthquakes, and the ionosphere. Eos, Transactions American Geophysical Union, 88(20), 217-218.

Pulinets, S. A. (2009). Physical mechanism of the vertical electric field generation over active tectonic faults. Advances in Space Research, 44(6), 767-773.

Pulinets, S. A., Boyarchuk, K. A., Hegai, V. V., \& Karelin, A. V. (2002). Conception and model of seismo-ionosphere-magnetosphere coupling. Seismo-Electromagnetics: Lithosphere-AtmosphereIonosphere Coupling, 353-361.

Pulinets, S. A., Contreras, A. L., Bisiacchi-Giraldi, G., \& Ciraolo, L. (2005). Total electron content variations in the ionosphere before the Colima, Mexico, earthquake of 21 January 2003. Geofísica internacional, 44(4), 369-377. 
Pulinets, S., \& Boyarchuk, K. (2004). Ionospheric precursors of earthquakes. Springer Science \& Business Media, $31-315$.

Shah, M., Ahmed, A., Ehsan, M., Khan, M., Tariq, M. A., Calabia, A., ur Rahman, Z. (2020). Total electron content anomalies associated with earthquakes occurred during 1998-2019. Acta Astronautica, 175, 268-276. doi:10.1016/j.actaastro.2020.06.005.

Shah, M., Aibar, A. C., Tariq, M. A., Ahmed, J., \& Ahmed, A. (2020). Possible ionosphere and atmosphere precursory analysis related to $\mathrm{Mw}>6.0$ earthquakes in Japan. Remote Sensing of Environment, 239, 111620.

Sharma, G., Mohanty, S., \& Kannaujiya, S. (2017a). Ionospheric TEC modelling for earthquakes precursors from GPS data. Quaternary International, 462, 65-74.

Sharma, G., Ray, P. C., \& Kannaujiya, S. (2019). Ionospheric Total Electron Content for Earthquake Precursor Detection. In Remote Sensing of Northwest Himalayan Ecosystems (pp. 57-66). Springer, Singapore.

Sharma, G., Saikia, P., Walia, D., Banerjee, P., \& Raju, P. L. N. (2021). TEC anomalies assessment for earthquakes precursors in North-Eastern India and adjoining region using GPS data acquired during 2012-2018. Quaternary International, 575, 120-129.

Shi, K., Guo, J., Liu, X., Liu, L., You, X., \& Wang, F. (2020). Seismo-ionospheric anomalies associated with Mw 7.8 Nepal earthquake on 201525 April from CMONOC GPS data. Geosciences Journal, 1-16.

Shi, K., Liu, X., Guo, J., Liu, L., You, X., \& Wang, F. (2019). Pre-earthquake and coseismic ionosphere disturbances of the Mw 6.6 Lushan earthquake on 20 April 2013 monitored by CMONOC. Atmosphere, 10(4), 216.

Silwal, A., Gautam, S. P., Chapagain, N. P., Karki, M., Poudel, P., Ghimire, B. D., Mishra, R. K., Adhikari B. (2021). Ionospheric Response over Nepal during the 26 December 2019 Solar Eclipse. Journal of Nepal Physical Society, 7(1), 25-30.

Silwal, A., Gautam, S. P., Poudel, P., Karki, M., Adhikari, B., Chapagain, N. P., et al. (2021). Global positioning system observations of ionospheric total electron content variations during the 15 January 2010 and 21 June 2020 solar eclipse. Radio Science, 56, e2020RS007215. https://doi. org/10.1029/2020RS007215

Usoro, A. E. (2015). Some basic properties of cross-correlation functions of n-dimensional vector time series. Journal of Statistical and Econometric Methods, 4(1), 63-71.

Wang, H. L., Chen, H. W., \& Zhu, L. (2010). Constraints on average Taiwan Reference Moho Discontinuity Model-receiver function analysis using BATS data. Geophysical Journal International, 183(1), 1-19. 
Yao, Y., Chen, P., Wu, H., Zhang, S., \& Peng, W. (2012). Analysis of ionospheric anomalies before the $2011 \mathrm{M}$ w 9.0 Japan earthquake. Chinese science bulletin, 57(5), 570-510. 